\title{
Research on the Dynamic Responses of Simply Supported Horizontal Pipes Conveying Gas-Liquid Two-Phase Slug Flow
}

\author{
Gang Liu ${ }^{1,2,3,4}$, Zongrui Hao ${ }^{1,2,3, * \mathbb{D}}$, Yueshe Wang ${ }^{4}$ and Wanlong Ren ${ }^{1,2,3}$ \\ 1 Institute of Oceanographic Instrumentation, Qilu University of Technology (Shandong Academy of Sciences), \\ Qingdao 266100, China; liu-g@qlu.edu.cn (G.L.); renwl@qlu.edu.cn (W.R.) \\ 2 Shandong Provincial Key Laboratory of Marine Monitoring Instrument Equipment Technology, \\ Qingdao 266100, China \\ 3 National Engineering and Technological Research Center of Marine Monitoring Equipment, \\ Qingdao 266100, China \\ 4 State Key Laboratory of Multiphase Flow in Power Engineering, Xi'an Jiaotong University, \\ Xi'an 710049, China; wangys@mail.xjtu.edu.cn \\ * Correspondence: haozr@qlu.edu.cn
}

Citation: Liu, G.; Hao, Z.; Wang, Y.; Ren, W. Research on the Dynamic Responses of Simply Supported Horizontal Pipes Conveying Gas-Liquid Two-Phase Slug Flow. Processes 2021, 9, 83. https:// doi.org/10.3390/pr9010083

Received: 15 November 2020 Accepted: 29 December 2020 Published: 2 January 2021

Publisher's Note: MDPI stays neutral with regard to jurisdictional clai$\mathrm{ms}$ in published maps and institutional affiliations.

Copyright: $(\odot 2021$ by the authors. Licensee MDPI, Basel, Switzerland. This article is an open access article distributed under the terms and conditions of the Creative Commons Attribution (CC BY) license (https:// creativecommons.org/licenses/by/ $4.0 /)$.

\begin{abstract}
The dynamic responses of simply supported horizontal pipes conveying gas-liquid twophase slug flow are explored. The intermittent characteristics of slug flow parameters are mainly considered to analyze the dynamic model of the piping system. The results show that the variations of the midpoint transverse displacement could vary from periodic-like motion to a kind of motion whose amplitude increases as time goes on if increasing the superficial gas velocity. Meanwhile, the dynamic responses have certain relations with the vibration acceleration. By analyzing the parameters in the power spectrum densities of vibration acceleration such as the number of predominant frequencies and the amplitude of each peak frequency, the dynamic behaviors of the piping system like periodicity could be calculated expediently.
\end{abstract}

Keywords: simply supported pipe; two-phase slug flow; intermittent; dynamic responses

\section{Introduction}

Fluid-conveying piping systems have been continually adopted in various processes of modern chemical engineering. It is crucial to guarantee the safety of the process of transporting materials. As is known, instability of the piping system may occur due to the vibrations induced by the internal flow, which has drawn the attention of numerous scholars. The explorations of the dynamics of the fluid-conveying piping system since the 1880s have been summarized systematically by Paidoussis and Issid [1].

It has been noted that with a sufficiently large constant flow velocity, divergence or flutter could happen for the piping system. In addition, for harmonically varying flow velocity, some complex dynamical behaviors like quasi-periodic may take place, which would bring more damages to the operation of the pipeline, which have been further confirmed by the researches of Ariaratnam and Namachchivaya [2] and Jin and Song [3]. Pipes conveying single-phase fluid have been researched deeply by scholars including the above several experts.

Actually, piping systems conveying two-phase flow may have a wider range of applications in science and engineering [4]. Alamian et al. [5] established a mathematical model to explore the instantaneous flow inside the gas pipelines. They discussed the effects of boundary conditions particularly. Goodarzi et al. [6] and [7] investigated the Erosion phenomenon in pipes conveying two-phase flow. Pourfattah et al. [8] carried out the twophase flow simulation of the heat transfer characteristics of the manifold microchannel heat sink. Almasi et al. [9] introduced an SPH method to explore the multiphase phenomenon. Shadloo et al. [10] discussed the pressure drop which is one significant parameter that 
would define the two-phase system in the pipe by the artificial neural networks. The effects of pressure drop on the dynamics of the piping system may be necessary to be explored in the future.

Due to the different proportions of flow rates of the two phases, several typical flow patterns could be observed in the pipes [11]. Among these flow regimes, slug flow has received more attention due to its intermittent features [12]. For instance, Dukler and Hubbard [13] and Zhang et al. [14] have developed their own models to calculate typical slug flow parameters. According to their researches, local slug flow parameters such as the velocities of gas and liquid would always vary with position and time, which would make the vibration of the slug flow piping system more complex. Riverin et al. [15], Cargnelutti et al. [16], Liu et al. [17], and Giraudeau et al. [18] indicated that the largest vibrations appeared in the slug flow system. An and Su [19] established a differential equation for a slug flow conveying riser subjected to vortex-induced force. They analyzed the variation of the transverse displacement for the riser with different flow rates.

Recently, the dynamics of piping systems conveying two-phase flow have been attracting the attention of scholars. Ebrahimi-Mamaghani et al. [20] emphasized the significance of flow parameters for the dynamic behaviors of the vertical piping system conveying two-phase flow. Sazesh and Shams [21] indicated the stabilities of the piping system could be affected markedly by time-varying phenomena like pulsating two-phase flow. Extraordinarily, some scholars paid attention to the piping system conveying two-phase slug flow. Khudayarov et al. [22] explored the relationships between some typical slug parameters such as the length of the gas bubble zone and the dynamic behaviors of the piping system. Zhu et al. [23] suggested that for a piping system conveying two-phase slug flow, the dynamic responses would be related to the intermittent characteristics of the slug flow. Cabrera-Miranda and Paik [24] pointed out that two significant parameters including the slugging frequencies and slug lengths should be deeply considered in the process of design for the piping system. It could be noted that the intermittent characteristics of slug flow leading to the dynamics of the piping system are extremely complicated.

Based on most scholars who are devoted to analyzing the dynamics of simply supported pipes conveying fluids, the flow parameters such as fluid velocity varying with the position of the pipe should be calculated. For the pipes conveying single-phase flow, the fluid velocity was supposed as constant along the pipe or written as a ripple value.

Nevertheless, for pipes conveying slug flow, the local flow velocity at every fixed cross section over the time of the passage of a slug unit would be equal to the velocity in the film zone for the case that a gas bubble passes the cross section at one moment while would be equal to the velocity in the slug zone for the case that a liquid slug passes the cross section at another moment, which was considered in this work. Then we can analyze the dynamics of the piping system corresponding to various working conditions of slug flow. While few scholars have analyzed the local flow parameters varying with time and position to explore the pipes conveying slug flow.

In general, the piping system conveying slug flow deserves deep concern with few scholars exploring the dynamic responses, which is the main objective of this study. The dynamic model will be established in Section 2. Galerkin's method is employed to discrete higher-order differential equations while the Runge Kutta method is introduced to obtain the variations of vibration parameters. Then the dynamic responses of the piping system under different conditions will be discussed in Section 3. Finally, some significant findings will be narrated in Section 4 .

\section{Materials and Methods}

A simply supported pipe conveying gas-liquid two-phase slug flow is depicted in Figure 1. It can be easily observed that the slug flow consists of several successive slug units. 


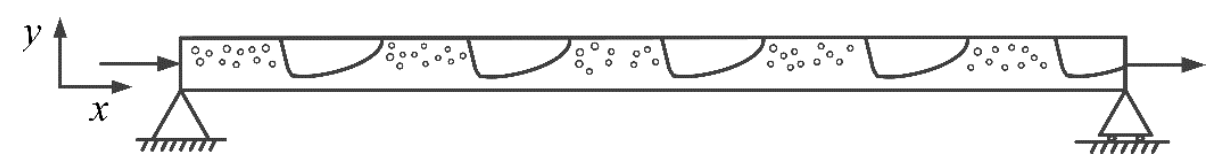

Figure 1. Schematic of a simply supported pipe conveying two-phase slug flow.

As shown in Figure 2, a gas bubble and a liquid slug would constitute one stable slug unit. It is assumed that the sectional area of the inner pipe is $A i$ and the volume flow rate is $Q$. Then the superficial gas velocity $u_{S G}$ and superficial liquid velocity $u_{S L}$ are obtained by:

$$
u_{S G}=\frac{Q_{G}}{A i}, u_{S L}=\frac{Q_{L}}{A i}
$$

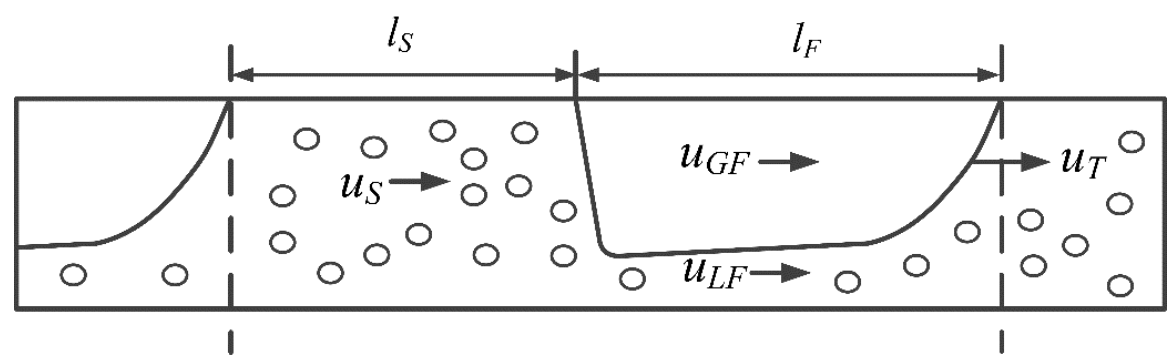

Figure 2. Schematic of a stable slug unit.

Referring to the work of Wang [25], the mathematical model of a slug flow conveying pipe could be written as:

$$
\begin{gathered}
E I \frac{\partial^{4} y}{\partial x^{4}}+2\left[m_{L}(x, t) u_{L}(x, t)+m_{G}(x, t) u_{G}(x, t)\right] \frac{\partial^{2} y}{\partial t \partial x}+\left[m_{L}(x, t) u_{L}^{2}(x, t)+m_{G}(x, t) u_{G}^{2}(x, t)\right] \frac{\partial^{2} y}{\partial x^{2}} \\
+\left[m_{L}(x, t)+m_{G}(x, t)+m_{P}\right] \frac{\partial^{2} y}{\partial t^{2}}-\left[\frac{E A i}{2 L} \int_{0}^{L}\left(\frac{\partial y}{\partial x}\right)^{2} d x\right] \frac{\partial^{2} y}{\partial x^{2}}=0
\end{gathered}
$$

The implications of the parameters of the above model could be found in the paper of Liu and Wang [26].

The transient pattern of slug flow at two typical moments is shown in Figure 3. It could be noted that $u_{L}(x, t)=u_{L F}$ at $t=t_{1}$ as shown in Figure 3 a while $u_{L}(x, t)=u_{S}$ at $t=t_{2}$ as depicted in Figure $3 b$, which means that $u_{L}(x, t)$ is the function of the coordinate $x$ and the time $t$. Then it is pivotal to obtain the variations of flow parameters with $x$ and $t$. to analyze Equation (2), which could be found in Liu and Wang [26].

(a)

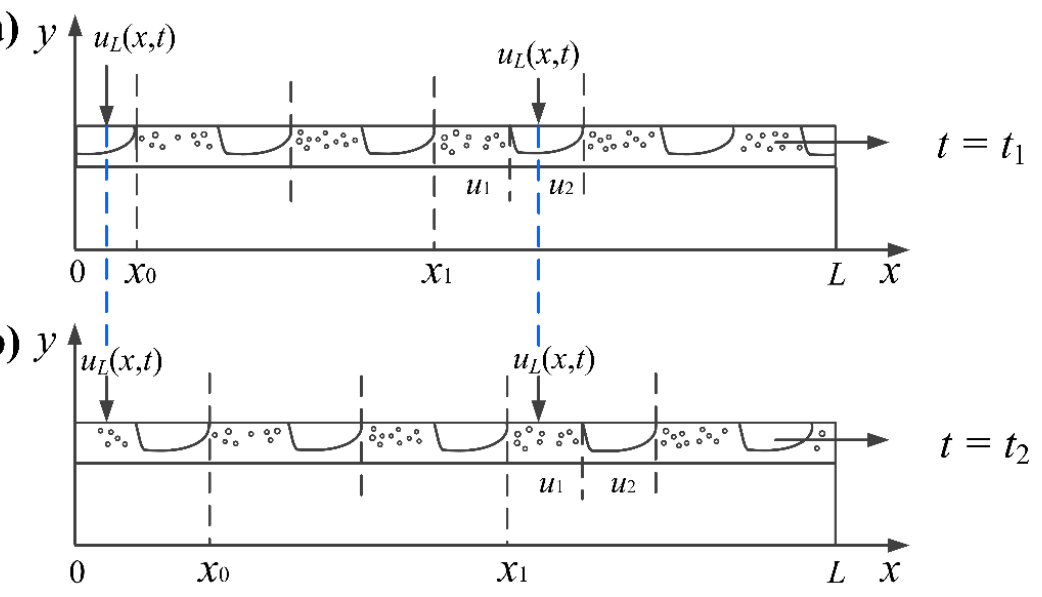

Figure 3. The transient pattern of slug flow in two typical moments $\left((\mathbf{a})\right.$ : at $t=t_{1} ;(\mathbf{b})$ : at $\left.t=t_{2}\right)$. 
The liquid flow velocity $u_{L}(0.5 L, t)$ is depicted in Figure 4 , which could reflect the features of intermittency. This characteristic will lead to some flow parameters in Equation (2) varying with time, which would affect the dynamic responses of the pipes greatly.

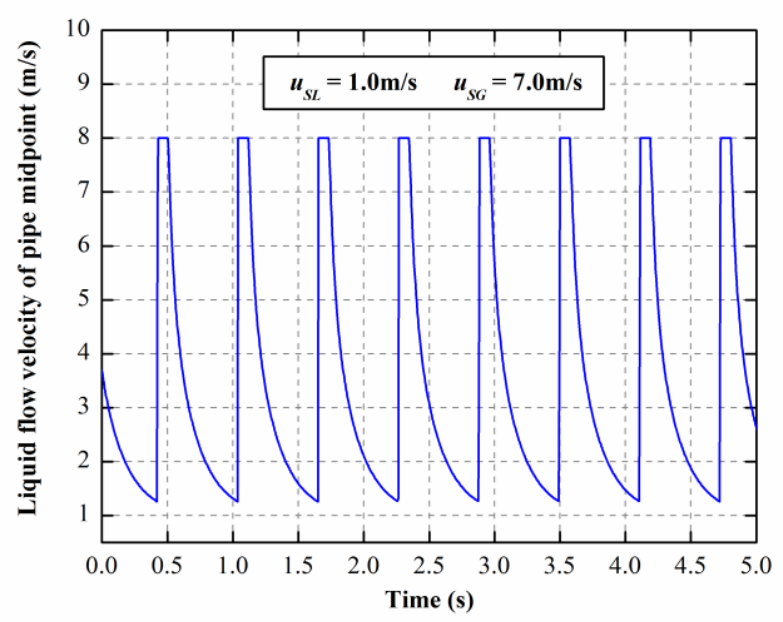

Figure 4. The liquid flow velocity at a fixed cross section located in the middle of the pipe over the time of the passage of several slug units.

Galerkin's method is employed in this work with the transverse displacement being written as:

$$
y(x, t)=\sum_{i=1}^{N} \varphi_{i}(x) q_{i}(t)=\boldsymbol{\Phi}^{T} \boldsymbol{q}
$$

where $\varphi_{i}(x)$ are the eigenfunctions of the simply supported beam and $q_{i}(t)$ are the generalized coordinates. Two-mode expansion $(n=2)$ is utilized in this study.

By means of substituting Equation (3) into Equation (2), left multiplying by $\boldsymbol{\Phi}$ and integrating it from 0 to $L$, the following matrix equation can be obtained after a series of operations:

$$
M \ddot{q}+C \dot{q}+K q=0
$$

where $M, C$ and $K$ are all two-order matrixes. The expressions of these matrixes could be referred to Liu and Wang [26]. It is supposed that $\boldsymbol{p}=[\boldsymbol{q}, \dot{\boldsymbol{q}}]^{T}$. Then Equation (4) is transferred to a differential equation:

$$
\dot{p}=E p
$$

The coefficient matrix $E$ is written as

$$
E=\left[\begin{array}{cc}
0 & I \\
-M^{-1} K & -M^{-1} C
\end{array}\right]
$$

where $I$ is the two-order unit matrixes. Considering the nonlinear factor, Equation (5) is a differential equation set that is calculated by the Runge Kutta method in this work. Then the variations of vibration parameters including vibration displacement, velocity, and acceleration with time could be obtained.

\section{Results and Discussion}

In this study, the inner diameter of the pipe $D i=0.025 \mathrm{~m}$, the outer diameter of the pipe $D=0.028 \mathrm{~m}$, the length of the pipe is $10 \mathrm{~m}$, the density of the fluid $\rho_{L}=998 \mathrm{~kg} / \mathrm{m}^{3}$, and the density of the gas $\rho_{G}=1.20 \mathrm{~kg} / \mathrm{m}^{3} . u_{S L}$ would be fixed as $1.0 \mathrm{~m} / \mathrm{s}$ with $u_{S G}$ varying from $3.0 \mathrm{~m} / \mathrm{s}$ to $10.0 \mathrm{~m} / \mathrm{s}$. The flow regimes of these conditions are all slug flow based on the flow pattern map mentioned in Zhang et al. [27]. In the following discussion, two kinds of pipe including Young's modulus $E=70 \mathrm{GPa}$ and $E=120 \mathrm{GPa}$ will be analyzed 
successively. The variations of the midpoint transverse displacement will be employed to represent the dynamic responses of the piping system.

\subsection{The Dynamic Responses of $E=70 \mathrm{GPa}$}

The bifurcation diagram of $E=70 \mathrm{GPa}$ is constructed to explore the dynamical behaviors of the piping system at different $u_{S G}$ and $u_{S L}$, which can be obtained by recording the midpoint displacement when the midpoint velocity is zero as shown in Figure 5. It is observed that the dynamical behaviors are similar to each other when $u_{S G}$ is less than $7.0 \mathrm{~m} / \mathrm{s}$. However, a great change of the dynamical behaviors would happen when $u_{S G}$ is larger than $7.0 \mathrm{~m} / \mathrm{s}$. Due to this, we will discuss the dynamic responses of the piping system under six conditions where $u_{S G}$ are $3.0,5.0,7.0,8.09 .0,10.0 \mathrm{~m} / \mathrm{s}$ respectively.

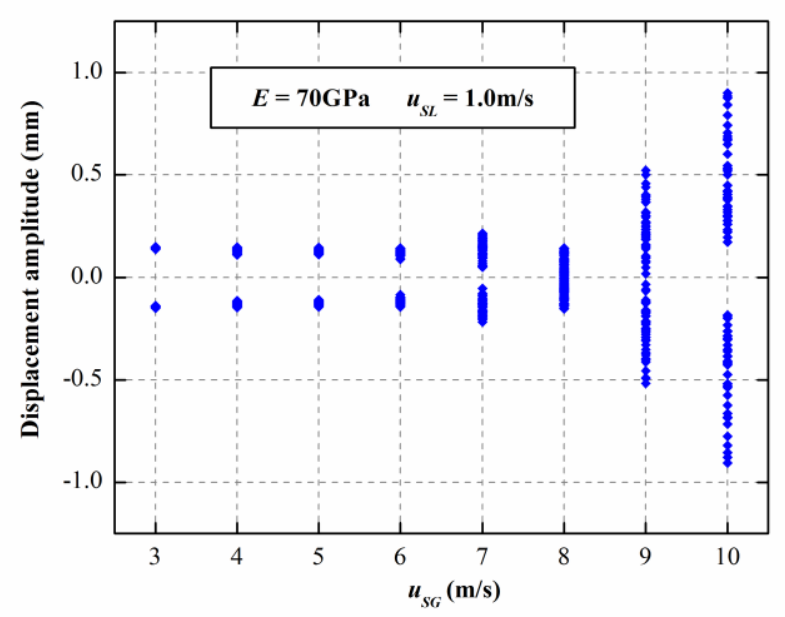

Figure 5. Bifurcation diagram for the midpoint of the piping system for $E=70 \mathrm{GPa}$.

The dynamic responses of the piping system for the case of $E=70 \mathrm{GPa}$ and $u_{S L}=1.0 \mathrm{~m} / \mathrm{s}$ at different $u_{S G}$ are shown in Figure 6. It is observed from Figure $6 \mathrm{a}, \mathrm{b}$ that the variations of the midpoint transverse displacement at $u_{S G}=3.0 \mathrm{~m} / \mathrm{s}$ and $u_{S G}=5.0 \mathrm{~m} / \mathrm{s}$ are both similar to a kind of cyclic motion but it is not the normal cyclic motion like simple harmonic motion on account of the amplitude of the piping system varying with time. The variation of the amplitude value at certain moments for $u_{S G}=5.0 \mathrm{~m} / \mathrm{s}$ is greater than that of $u_{S G}=3.0 \mathrm{~m} / \mathrm{s}$. Nevertheless, some differences may exist for the variations of the period of these two cases. With the increase of $u_{S G}$, the variations of the midpoint transverse displacement would change considerably. For the case of $u_{S G}=7.0 \mathrm{~m} / \mathrm{s}$ as shown in Figure $6 \mathrm{c}$, the absolute value of the amplitude increases gradually with the lapse of time in the first 30 seconds. However, the decrease of the amplitude would take place in the second 30 seconds. Although we mainly discuss the dynamic responses of the first 60 seconds in this study, it can be speculated that the increase and decrease may still continue to appear alternately as time goes on further. It is worth noting that the variations of the midpoint transverse displacement of $u_{S G}=8.0 \mathrm{~m} / \mathrm{s}$ are different from those of $u_{S G}=7.0 \mathrm{~m} / \mathrm{s}$ completely as depicted in Figure $6 \mathrm{~d}$. The increase and decrease of the absolute value of the amplitude appear alternately within a short time. When $u_{S G}$ increases to $9 \mathrm{~m} / \mathrm{s}$ as shown in Figure 6e, the midpoint transverse displacement seems to perform a similar varying pattern of the case of $u_{S G}=7.0 \mathrm{~m} / \mathrm{s}$. At the beginning stage of the vibration, the absolute value of the amplitude increases first and then decreases just like the condition of $u_{S G}=7.0 \mathrm{~m} / \mathrm{s}$. This state will continue about four times for 40 seconds. Yet the amplitude will continue to increase as time goes on. The condition of $u_{S G}=10.0 \mathrm{~m} / \mathrm{s}$ as shown in Figure $6 \mathrm{f}$ is similar to the condition of $u_{S G}=9.0 \mathrm{~m} / \mathrm{s}$. In summary, with the increase of superficial gas velocity, the dynamic responses will vary from periodic-like motion to a kind of motion whose amplitude increases with time. 

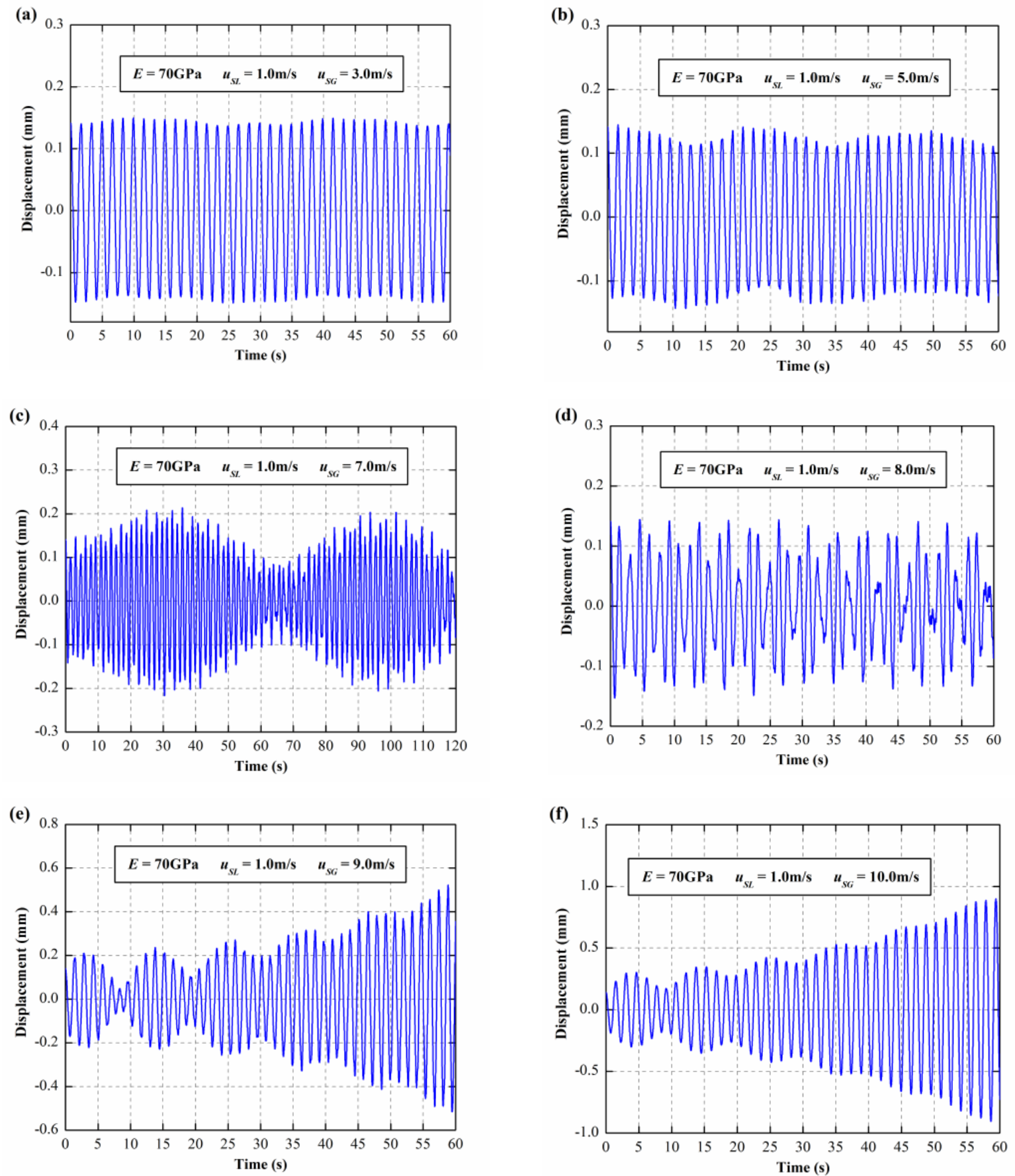

Figure 6. Midpoint displacement of the piping system for $E=70 \mathrm{GPa}$ and $u_{S L}=1.0 \mathrm{~m} / \mathrm{s}\left((\mathbf{a}): u_{S G}=3.0 \mathrm{~m} / \mathrm{s}\right.$; (b): $\left.u_{S G}=5.0 \mathrm{~m} / \mathrm{s} ;(\mathbf{c}): u_{S G}=7.0 \mathrm{~m} / \mathrm{s} ;(\mathbf{d}): u_{S G}=8.0 \mathrm{~m} / \mathrm{s} ;(\mathbf{e}): u_{S G}=9.0 \mathrm{~m} / \mathrm{s} ;(\mathbf{f}): u_{S G}=10.0 \mathrm{~m} / \mathrm{s}\right)$.

The vibration acceleration can be employed to explain the dynamic responses of the piping system. The power spectrum densities (PSD) of the vibration acceleration for various superficial gas velocities $E=70 \mathrm{GPa}$ and $u_{S L}=1.0 \mathrm{~m} / \mathrm{s}$ are shown in Figure 7 . The PSD of the acceleration is obtained from the method of Fast Fourier Transform (FFT) for the calculated vibration acceleration signal. 

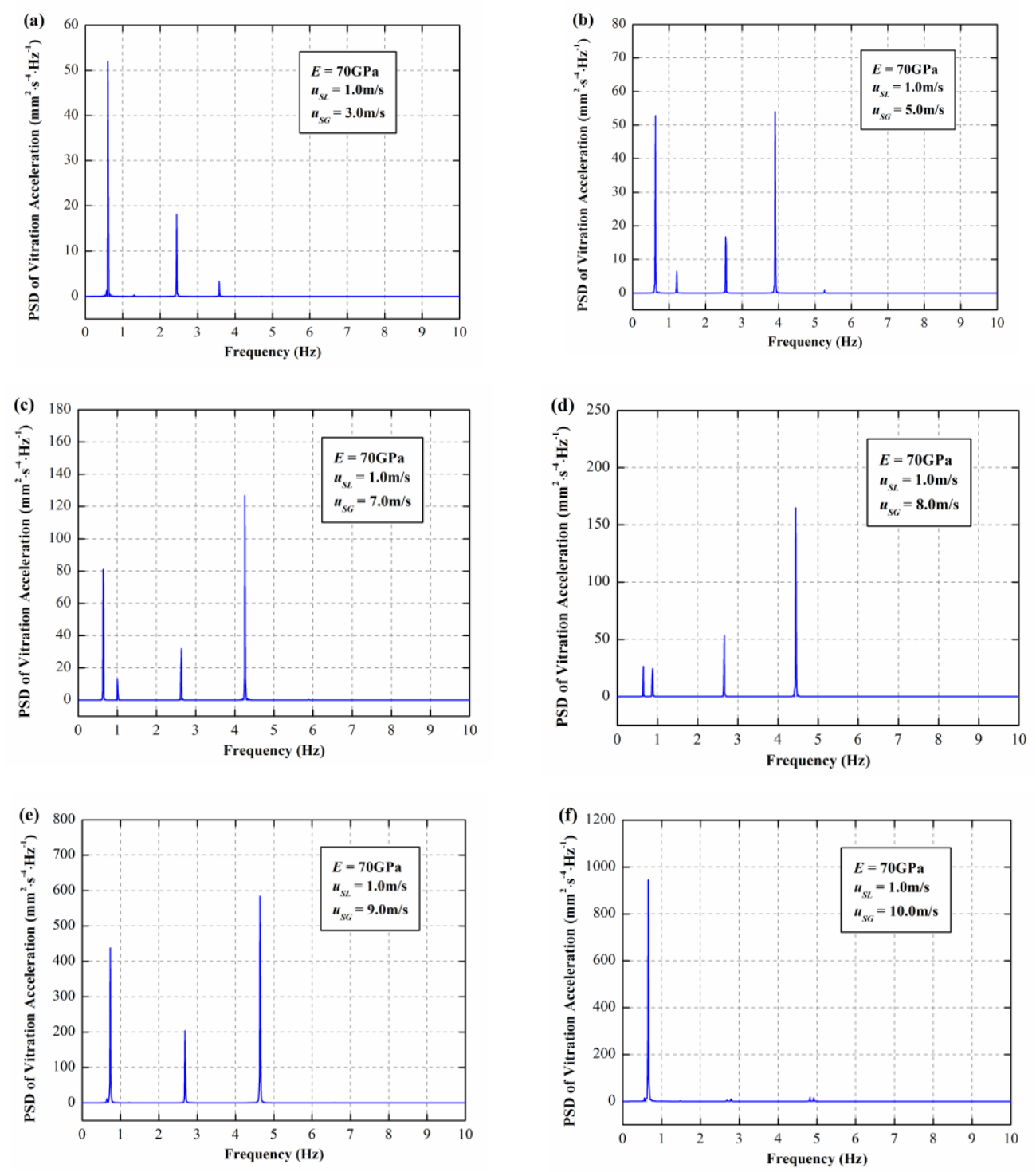

Figure 7. Power spectrum densities of the vibration acceleration for $E=70 \mathrm{GPa}$ and $u_{S L}=1.0 \mathrm{~m} / \mathrm{s}\left((\mathbf{a}): u_{S G}=3.0 \mathrm{~m} / \mathrm{s} ;(\mathbf{b})\right.$ : $\left.u_{S G}=5.0 \mathrm{~m} / \mathrm{s} ;(\mathbf{c}): u_{S G}=7.0 \mathrm{~m} / \mathrm{s} ;(\mathbf{d}): u_{S G}=8.0 \mathrm{~m} / \mathrm{s} ;(\mathbf{e}): u_{S G}=9.0 \mathrm{~m} / \mathrm{s} ;(\mathbf{f}): u_{S G}=10.0 \mathrm{~m} / \mathrm{s}\right)$.

It can be immediately found that visible distinctions exist with an increase of $u_{S G}$. In Figure 7a, three predominant frequencies could be observed with the amplitude decreasing as the peak frequency increases. When the superficial gas velocity is $5.0 \mathrm{~m} / \mathrm{s}$, four predominant frequencies exist as shown in Figure $7 \mathrm{~b}$, which could prove that some differences may exist for the variations of the period of these two cases as mentioned above. The amplitudes of the minimum peak frequency and the maximal peak frequency are almost the same. While the amplitudes of second and third peak frequencies are relatively small. The condition of $u_{S L}=7.0 \mathrm{~m} / \mathrm{s}$ as depicted in Figure $7 \mathrm{c} \mathrm{seems} \mathrm{to} \mathrm{be} \mathrm{similar} \mathrm{to} \mathrm{the}$ condition of $u_{S G}=5.0 \mathrm{~m} / \mathrm{s}$. However, the amplitude of the maximal peak frequency is larger than that of the minimum peak frequency. It was noted that the midpoint transverse displacement would no longer present the characteristic of periodicity when the superficial gas velocity is larger than $7.0 \mathrm{~m} / \mathrm{s}$. Some interesting phenomena will also occur for these conditions. Firstly, four predominant frequencies exist in the case of $u_{S G}=8.0 \mathrm{~m} / \mathrm{s}$ as shown in Figure $7 \mathrm{~d}$. The amplitudes of first and second peak frequencies are both very small. As the peak frequency further increases, the amplitude will get bigger as well. Secondly, when the superficial gas velocity increases to $10.0 \mathrm{~m} / \mathrm{s}$, only one obvious predominant frequency could be found as depicted in Figure $7 \mathrm{f}$. It could be noted that the 
PSD for the case of $u_{S G}=7.0 \mathrm{~m} / \mathrm{s}$ and $u_{S G}=9.0 \mathrm{~m} / \mathrm{s}$ are similar to each other. Merely one main peak with small amplitude exists in the case of $u_{S G}=7.0 \mathrm{~m} / \mathrm{s}$. Then it seems that conspicuous discrepancies exist in the vibration shapes for these two cases, which means that the analysis of PSD of vibration acceleration could really reflect the dynamic responses of the piping system.

\subsection{The Dynamic Responses of $E=120 \mathrm{GPa}$}

The bifurcation diagram of $E=120 \mathrm{GPa}$ is shown in Figure 8. It can be found that the dynamical behavior of $u_{S G}=8.0 \mathrm{~m} / \mathrm{s}$ seems to be different from other conditions. Yet it is much similar to the situation of $u_{S G}=10.0 \mathrm{~m} / \mathrm{s}$ for $E=70 \mathrm{GPa}$. In the same way, we will discuss the dynamic responses of the piping system of six conditions as shown in Figure 9.

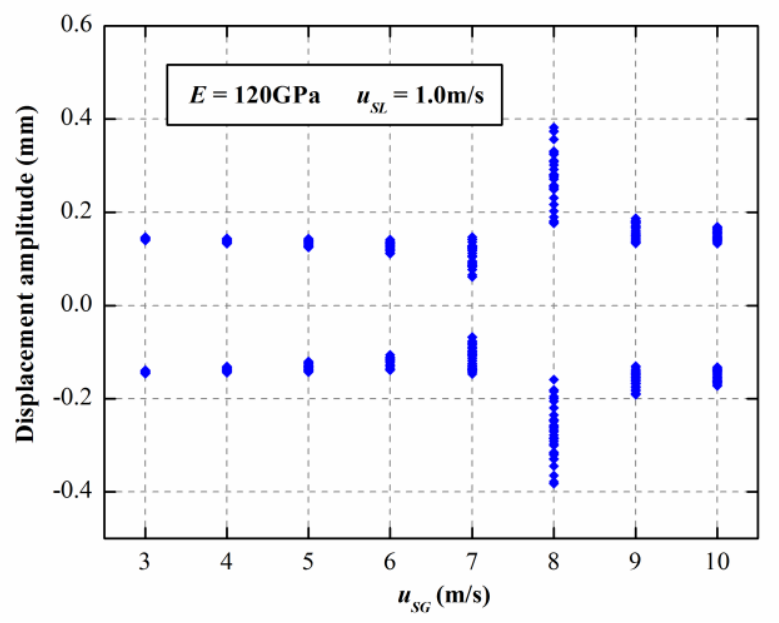

Figure 8. Bifurcation diagram for the midpoint of the piping system for $E=120 \mathrm{GPa}$.
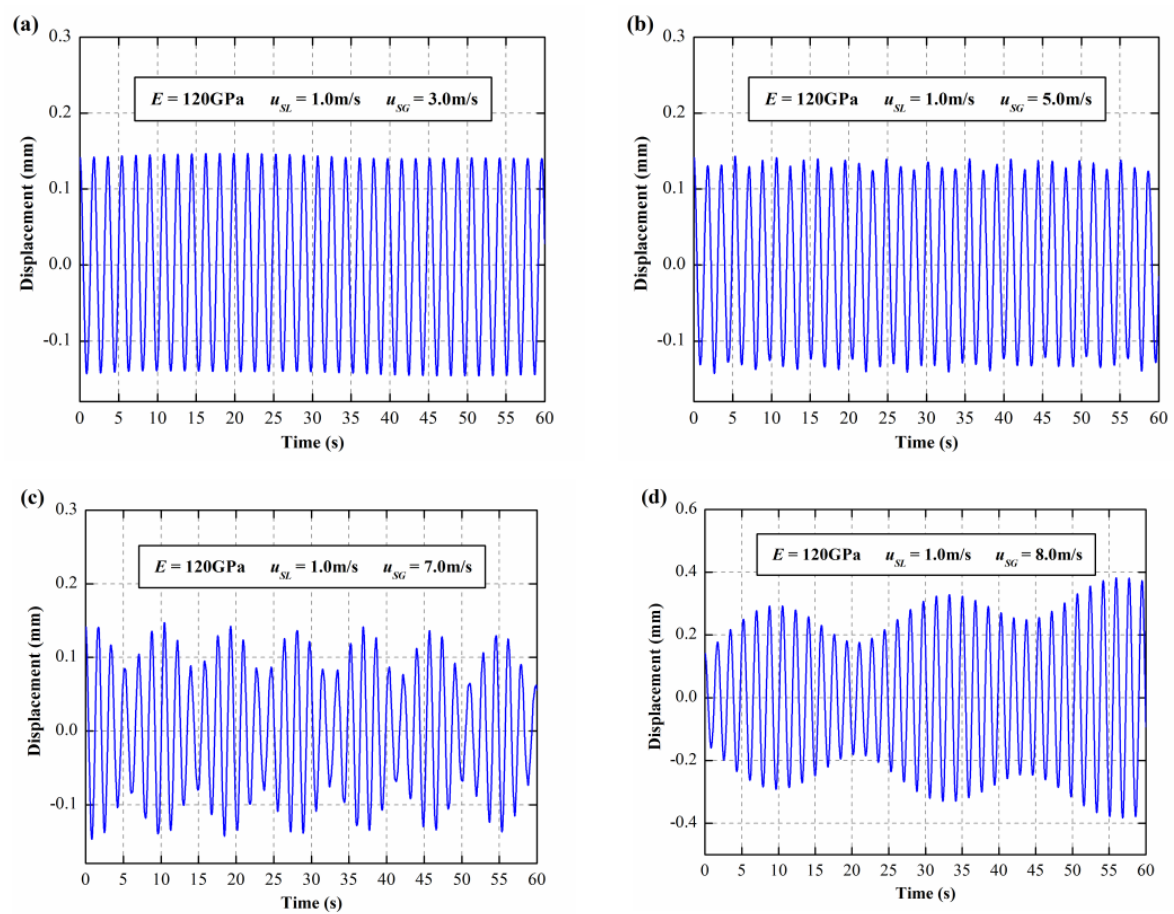

Figure 9. Cont. 

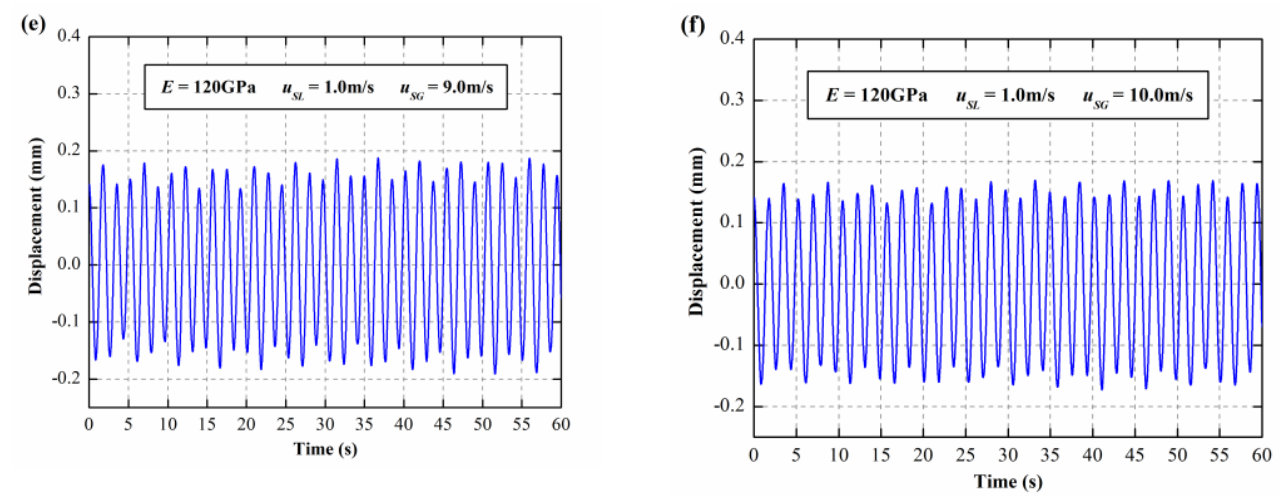

Figure 9. Midpoint displacement of the piping system for $E=120 \mathrm{GPa}$ and $u_{S L}=1.0 \mathrm{~m} / \mathrm{s}\left((\mathbf{a}): u_{S G}=3.0 \mathrm{~m} / \mathrm{s}\right.$; $(\mathbf{b})$ : $\left.u_{S G}=5.0 \mathrm{~m} / \mathrm{s} ;(\mathbf{c}): u_{S G}=7.0 \mathrm{~m} / \mathrm{s} ;(\mathbf{d}): u_{S G}=8.0 \mathrm{~m} / \mathrm{s} ;(\mathbf{e}): u_{S G}=9.0 \mathrm{~m} / \mathrm{s} ;(\mathbf{f}): u_{S G}=10.0 \mathrm{~m} / \mathrm{s}\right)$.

It can be immediately found that the dynamic responses of $E=120 \mathrm{GPa}$ have certain differences from those of $E=70 \mathrm{GPa}$. The variations of the midpoint transverse displacement are all similar to a kind of cyclic motion unless the situation of $u_{S G}=8.0 \mathrm{~m} / \mathrm{s}$. The variation of $u_{S G}=3.0 \mathrm{~m} / \mathrm{s}$ is almost periodic vibration as shown in Figure 9. As shown in Figure $9 \mathrm{~b}, \mathrm{e}$, and $\mathrm{f}$, the dynamic responses with $u_{S G}=5.0 \mathrm{~m} / \mathrm{s}, u_{S G}=9.0 \mathrm{~m} / \mathrm{s}$ and $u_{S G}=10.0 \mathrm{~m} / \mathrm{s}$ are all similar to periodic vibration with the amplitude of the piping system varying as time goes on. Merely the amplitudes of $u_{S G}=9.0 \mathrm{~m} / \mathrm{s}$ and $u_{S G}=10.0 \mathrm{~m} / \mathrm{s}$ are larger than that of $u_{S G}=5.0 \mathrm{~m} / \mathrm{s}$. In the case of $u_{S G}=7.0 \mathrm{~m} / \mathrm{s}$ as shown in Figure $9 \mathrm{c}$, periodic vibration could also be observed which is similar to the variation of $u_{S G}=7.0 \mathrm{~m} / \mathrm{s}$ for $E=70 \mathrm{GPa}$ as shown in Figure 6c yet with a shorter cycle. The dynamic response of $u_{S G}=8.0 \mathrm{~m} / \mathrm{s}$ is still distinctive as shown in Figure $9 \mathrm{~d}$. The amplitude will continue to increase as time goes on. In summary, like the case of $E=70 \mathrm{GPa}$, with the increase of superficial gas velocity, the dynamic responses will vary from periodic-like motion to a kind of motion whose amplitude increases with time. However, with the further increase of superficial gas velocity, the dynamic response will regain the periodic-like motion yet the amplitude will become larger.

The power spectrum densities (PSD) of the vibration acceleration for various superficial gas velocities $E=120 \mathrm{GPa}$ and $u_{S L}=1.0 \mathrm{~m} / \mathrm{s}$ are shown in Figure 10 .
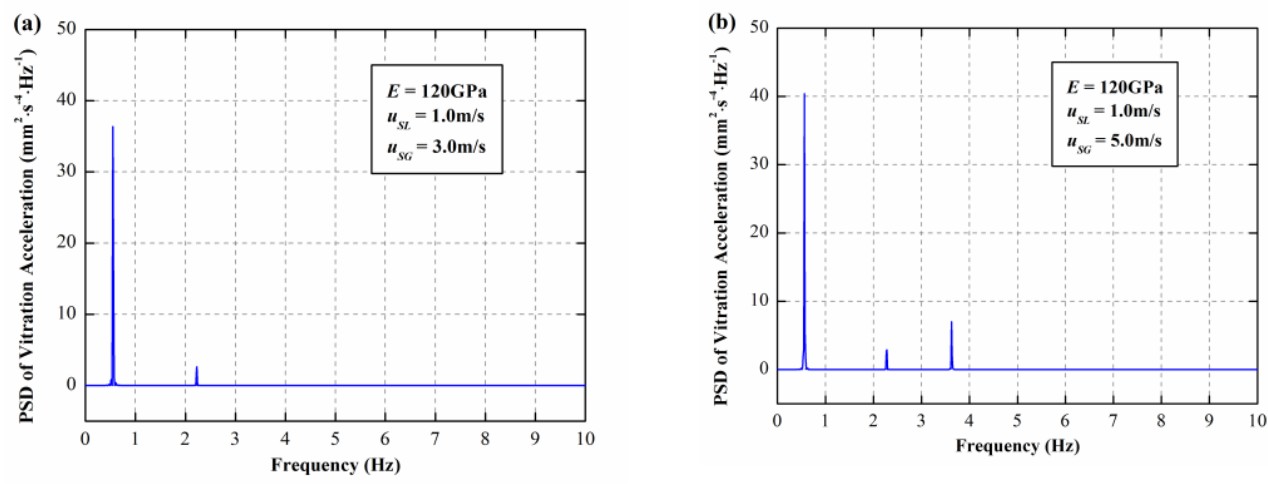

Figure 10. Cont. 

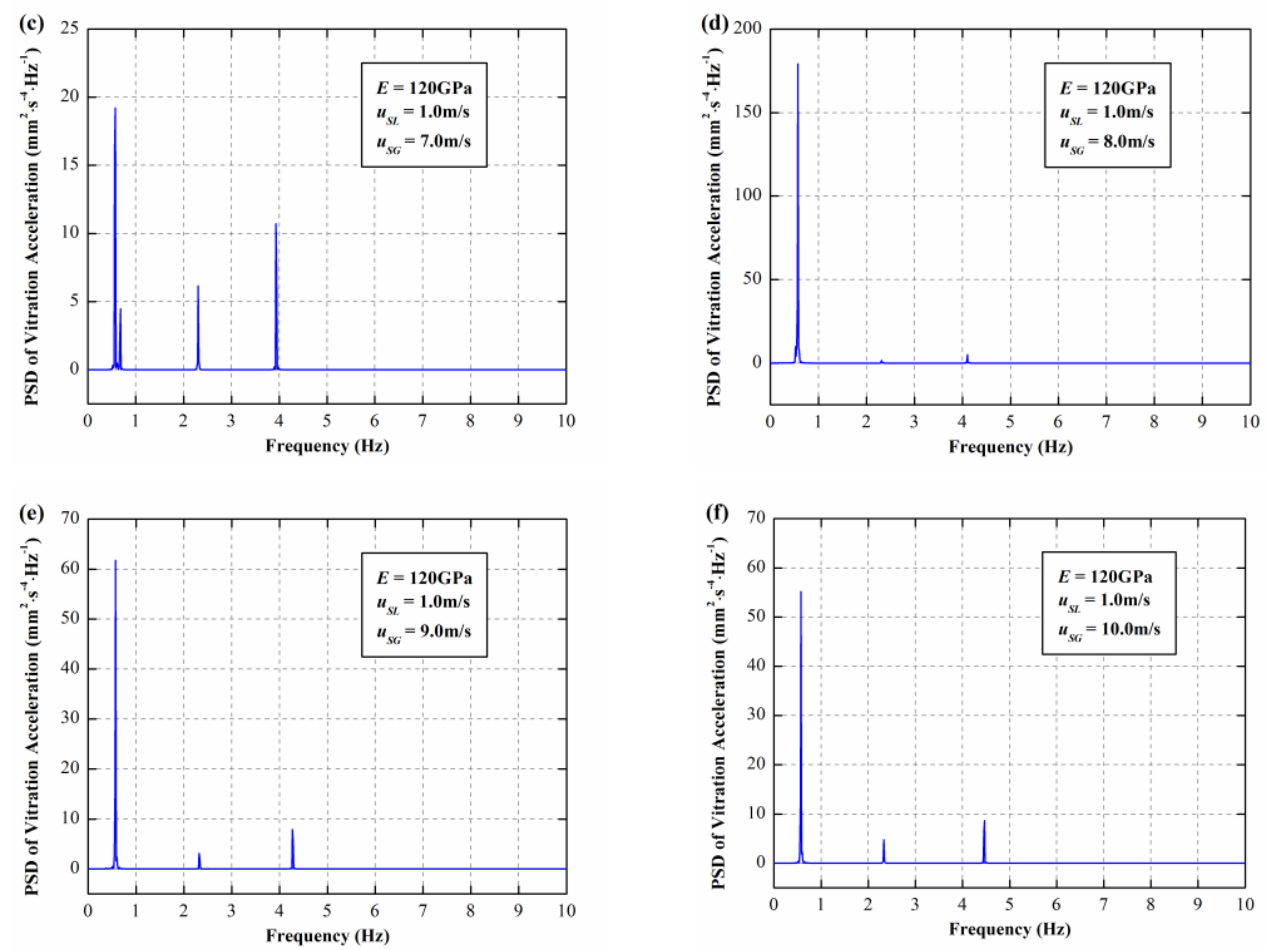

Figure 10. Power spectrum densities of the vibration acceleration for $E=120 \mathrm{GPa}$ and $u_{S L}=1.0 \mathrm{~m} / \mathrm{s}\left((\mathbf{a}): u_{S G}=3.0 \mathrm{~m} / \mathrm{s} ;(\mathbf{b})\right.$ : $\left.u_{S G}=5.0 \mathrm{~m} / \mathrm{s} ;(\mathbf{c}): u_{S G}=7.0 \mathrm{~m} / \mathrm{s} ;(\mathbf{d}): u_{S G}=8.0 \mathrm{~m} / \mathrm{s} ;(\mathbf{e}): u_{S G}=9.0 \mathrm{~m} / \mathrm{s} ;(\mathbf{f}): u_{S G}=10.0 \mathrm{~m} / \mathrm{s}\right)$.

In the following discussion, "the first" peak frequency will be employed to represent the smallest peak frequency. "The second" will be the peak frequency which is just larger than "the first". The rest can be done in the same manner. Two predominant frequencies could be observed In Figure 10a. The second peak frequency is about 13 orders of magnitude smaller compared to the first one. The dynamic responses with $u_{S G}=5.0 \mathrm{~m} / \mathrm{s}, u_{S G}=9.0 \mathrm{~m} / \mathrm{s}$ and $u_{S G}=10.0 \mathrm{~m} / \mathrm{s}$ are similar to each other. Then the power spectrum densities (PSD) of the vibration acceleration of these three conditions all have three predominant frequencies with the amplitude of the first peak frequency being greater than those of the second and third ones as shown in Figure 10b. There are four predominant frequencies when the superficial gas velocity is $7.0 \mathrm{~m} / \mathrm{s}$ with the first one having the largest amplitude as depicted in Figure 10(c). It is worth noting that the variations of the midpoint transverse displacement of $u_{S G}=9.0 \mathrm{~m} / \mathrm{s}$ and $u_{S G}=10.0 \mathrm{~m} / \mathrm{s}$ for $E=70 \mathrm{GPa}$ and $u_{S G}=8.0 \mathrm{~m} / \mathrm{s}$ for $E=120 \mathrm{GPa}$ are similar to each other, but the PSD of $u_{S G}=9.0 \mathrm{~m} / \mathrm{s}$ is much different from those of $E=70 \mathrm{GPa}$ and $u_{S G}=8.0 \mathrm{~m} / \mathrm{s}$ for $E=120 \mathrm{GPa}$. The phase portraits of the piping system are employed to explain this phenomenon as shown in Figure 11. It can be immediately found that the piping system may undergo a kind of chaotic-like motion for $u_{S G}=9.0 \mathrm{~m} / \mathrm{s}$ and $E=70 \mathrm{GPa}$ in Figure 11a which is different from the dynamic behaviors of $u_{S G}=10.0 \mathrm{~m} / \mathrm{s}$ for $E=70 \mathrm{GPa}$ and $u_{S G}=8.0 \mathrm{~m} / \mathrm{s}$ for $E=120 \mathrm{GPa}$. It should be noted that the chaotic-like motion does not have to occur for the higher gas flow rate as the slug parameters would affect the dynamic behaviors of the piping system a lot, which means that the slug parameters induced by the intermittent characteristics should be particularly considered to obtain the dynamic behaviors. 

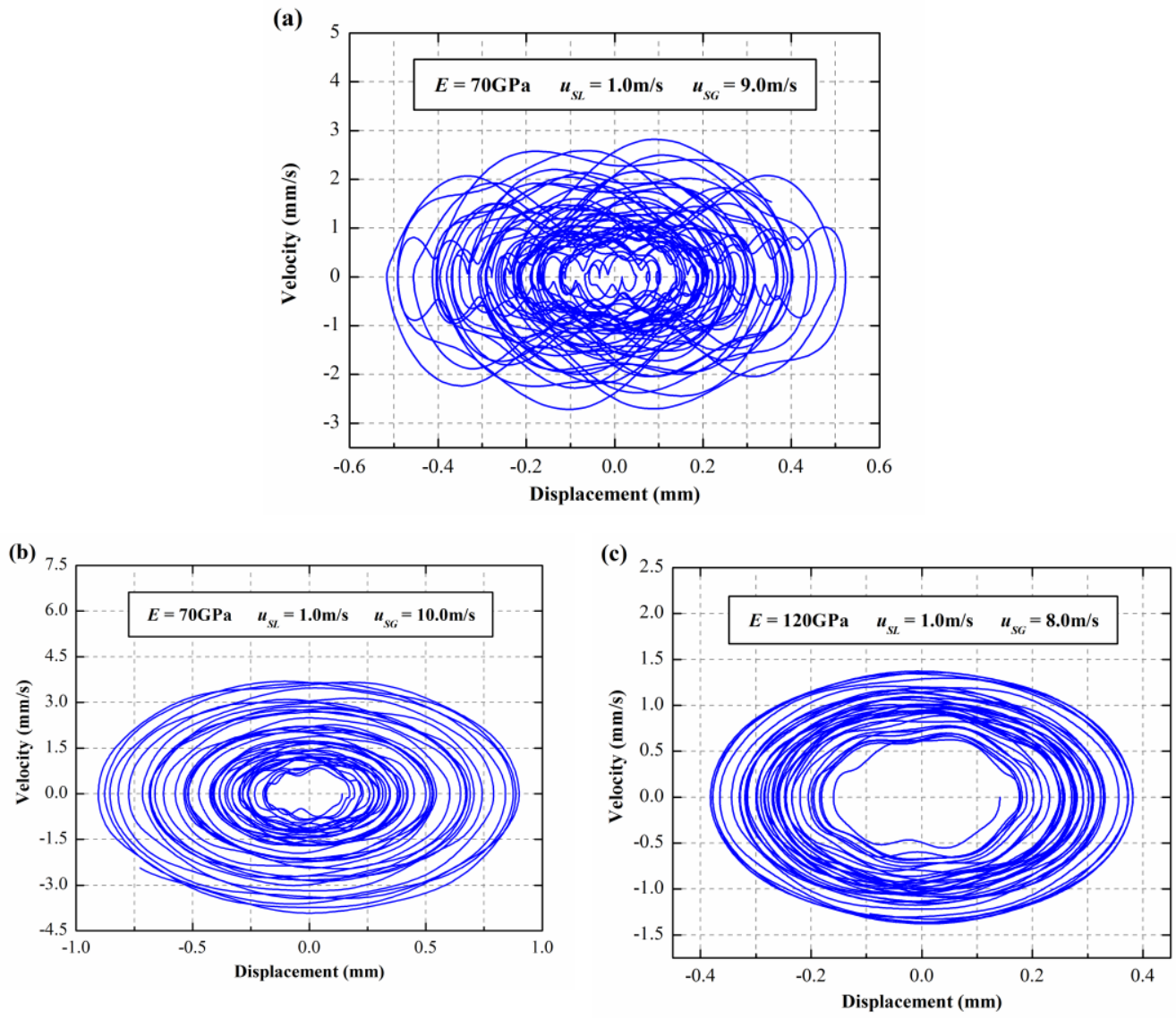

Figure 11. Phase portraits of several typical conditions ((a): $E=70 \mathrm{GPa}, u_{S L}=1.0 \mathrm{~m} / \mathrm{s}, u_{S G}=9.0 \mathrm{~m} / \mathrm{s} ;(\mathbf{b}): E=70 \mathrm{GPa}$, $\left.u_{S L}=1.0 \mathrm{~m} / \mathrm{s}, u_{S G}=10.0 \mathrm{~m} / \mathrm{s} ;(\mathbf{c}): E=120 \mathrm{GPa}, u_{S L}=1.0 \mathrm{~m} / \mathrm{s}, u_{S G}=8.0 \mathrm{~m} / \mathrm{s} ;\right)$.

\section{Conclusions}

Based on slug flow parameters, the dynamic model for a simply supported piping system conveying two-phase slug flow is established to analyze the dynamic responses of the piping system under several pipe materials and superficial gas and liquid velocities. Some conclusions are listed as follows:

(1) For various pipe materials, the dynamic responses of the piping system perform different patterns. The variations of the midpoint transverse displacement for $E=70 \mathrm{GPa}$ and $E=120 \mathrm{GPa}$ will vary from periodic-like motion to a kind of motion whose amplitude increases as time goes on with the increase of superficial gas velocity. However, for $E=120 \mathrm{GPa}$ the dynamic response will regain the periodic-like motion with the further increase of superficial gas velocity.

(2) The dynamic responses have certain relations with the vibration acceleration. Firstly, if there are four predominant frequencies in the PSDs of the vibration acceleration, the piping system will perform periodic-like motion yet with the amplitude varying as time goes on. Secondly, if there are three predominant frequencies with the first peak frequency having the largest amplitude, the dynamic response will present the characteristic of periodic while the vibration amplitude varies with time in each periodic. Finally, the amplitude of the midpoint transverse displacement may continue to increase. For this case, if there is only one peak frequency that occupies the dominant status, the dynamic responses will follow certain rules. Otherwise, the piping system may perform a kind of chaotic-like motion. 
Author Contributions: Conceptualization, Z.H. and Y.W.; methodology, G.L.; software, G.L.; validation, W.R.; formal analysis, G.L.; investigation, G.L. and W.R; resources, G.L.; data curation, G.L.; writing_-original draft preparation, G.L.; writing_review and editing, Z.H.; visualization, Y.W.; supervision, Z.H.; project administration, Y.W.; funding acquisition, G.L. and Z.H. All authors have read and agreed to the published version of the manuscript.

Funding: This research was funded by the National Key Research and Development Program of China (grant number SQ2019YFC140019-03), the Shandong Key Research and Development Program (grant number 2019JZZY010819), project ZR2020QE192 supported by the Shandong Provincial Natural, Shandong Key Research and Development Program (grant number 2019GGX104042), and the Science and Technology Project of Qilu University of Technology (Shandong Academy of Sciences) (grant number 2020QN0024).

Institutional Review Board Statement: Not applicable.

Informed Consent Statement: Not applicable.

Data Availability Statement: Data is contained within the article.

Acknowledgments: The authors would like to thank the editors and reviewers for their valuable and constructive comments.

Conflicts of Interest: The authors declare no conflict of interest.

\section{Nomenclature}

$\begin{array}{ll}A i & \text { sectional area of the inner pipe, } \mathrm{m}^{2} \\ E & \text { Young's modulus of the pipe, GPa } \\ I & \text { inertial moment of cross-section area, } \mathrm{m}^{4} \\ L & \text { length of the pipe, } \mathrm{m} \\ m_{L}(x, t) & \text { mass of liquid phase per unit length at the coordinate } \mathrm{x} \text { and moment } \mathrm{t}, \mathrm{kg} / \mathrm{m} \\ m_{G}(x, t) & \text { mass of gas phase per unit length at the coordinate } \mathrm{x} \text { and moment } \mathrm{t}, \mathrm{kg} / \mathrm{m} \\ m_{P} & \text { mass of fluid per unit length, } \mathrm{kg} / \mathrm{m} \\ Q_{G} & \text { volume flow rates of the gas, } \mathrm{m}^{3} / \mathrm{s} \\ Q_{L}, & \text { volume flow rates of the liquid, } \mathrm{m}^{3} / \mathrm{s} \\ u_{L}(x, t) & \text { local velocity of liquid phase at the coordinate } \mathrm{x} \text { and moment } \mathrm{t}, \mathrm{m} / \mathrm{s} \\ u_{G}(x, t) & \text { local velocity of gas phase at the coordinate } \mathrm{x} \text { and moment } \mathrm{t}, \mathrm{m} / \mathrm{s} \\ u_{S G} & \text { superficial gas velocity, } \mathrm{m} / \mathrm{s} \\ u_{S L} & \text { superficial liquid velocity, } \mathrm{m} / \mathrm{s} \\ y & \text { transverse displacement of the pipe, } \mathrm{m} \\ \text { Greek } & \\ \text { symbols } & \\ \rho & \\ \text { Subscripts } & \text { density, } \mathrm{kg} / \mathrm{m}^{3} \\ L & \text { liquid phase } \\ G & \text { gas phase }\end{array}$

\section{References}

1. Païdoussis, M.; Issid, N. Dynamic stability of pipes conveying fluid. J. Sound Vib. 1974, 33, 267-294. [CrossRef]

2. Ariaratnam, S.; Namachchivaya, N.S. Dynamic stability of pipes conveying pulsating fluid. J. Sound Vib. 1986, 107, 215-230. [CrossRef]

3. Jin, J.; Song, Z. Parametric resonances of supported pipes conveying pulsating fluid. J. Fluids Struct. 2005, 20, 763-783. [CrossRef]

4. Miwa, S.; Mori, M.; Hibiki, T. Two-phase flow induced vibration in piping systems. Prog. Nucl. Energy 2015, 78, 270-284. [CrossRef]

5. Alamian, R.; Behbahani-Nejad, M.; Ghanbarzadeh, A. A state space model for transient flow simulation in natural gas pipelines. J. Nat. Gas Sci. Eng. 2012, 9, 51-59. [CrossRef]

6. Goodarzi, M.; Safaei, M.R.; Vafai, K.; Ahmadi, G.; Dahari, M.; Kazi, S.; Jomhari, N. Investigation of nanofluid mixed convection in a shallow cavity using a two-phase mixture model. Int. J. Therm. Sci. 2014, 75, 204-220. [CrossRef]

7. Safaei, M.R.; Mahian, O.; Garoosi, F.; Hooman, K.; Karimipour, A.; Kazi, S.N.; Gharehkhani, S. Investigation of Micro- and Nanosized Particle Erosion in a 90 Pipe Bend Using a Two-Phase Discrete Phase Model. Sci. World J. 2014, 2014, 1-12. [CrossRef]

8. Pourfattah, F.; Arani, A.A.A.; Babaie, M.R.; Nguyen, H.M.; Asadi, A. On the thermal characteristics of a manifold microchannel heat sink subjected to nanofluid using two-phase flow simulation. Int. J. Heat Mass Transf. 2019, 143, 118518. [CrossRef] 
9. Almasi, F.; Shadloo, M.; Hadjadj, A.; Ozbulut, M.; Tofighi, N.; Yildiz, M. Numerical simulations of multi-phase electrohydrodynamics flows using a simple incompressible smoothed particle hydrodynamics method. Comput. Math. Appl. 2021, 81, 772-785. [CrossRef]

10. Shadloo, M.; Rahmat, A.; Karimipour, A.; Wongwises, S. Estimation of Pressure Drop of Two-Phase Flow in Horizontal Long Pipes Using Artificial Neural Networks. J. Energy Resour. Technol. 2020, 142, 1-21. [CrossRef]

11. Cheng, L.; Ribatski, G.; Thome, J.R. Two-Phase Flow Patterns and Flow-Pattern Maps: Fundamentals and Applications. Appl. Mech. Rev. 2008, 61, 050802. [CrossRef]

12. Al-Safran, E. Investigation and prediction of slug frequency in gas/liquid horizontal pipe flow. J. Pet. Sci. Eng. 2009, 69, 143-155. [CrossRef]

13. Dukler, A.E.; Hubbard, M.G. A Model for Gas-Liquid Slug Flow in Horizontal and Near Horizontal Tubes. Ind. Eng. Chem. Fundam. 1975, 14, 337-347. [CrossRef]

14. Zhang, H.-Q.; Wang, Q.; Sarica, C.; Brill, J.P. Unified model for gas-liquid pipe flow via slug dynamics-part 1: Model development. Trans. ASME J. Energy Resour. Technol. 2003, 125, 266-273. [CrossRef]

15. Riverin, J.; De Langre, E.; Pettigrew, M.J. Fluctuating forces caused by internal two-phase flow on bends and tees. J. Sound Vib. 2006, 298, 1088-1098. [CrossRef]

16. Cargnelutti, M.F.; Belfroid, S.P.C.; Schiferli, W. Two-Phase Flow-Induced Forces on Bends in Small Scale Tubes. J. Press. Vessel. Technol. 2010, 132, 041305. [CrossRef]

17. Liu, Y.; Miwa, S.; Hibiki, T.; Ishii, M.; Morita, H.; Kondoh, Y.; Tanimoto, K. Experimental study of internal two-phase flow induced fluctuating force on a $90^{\circ}$ elbow. Chem. Eng. Sci. 2012, 76, 173-187. [CrossRef]

18. Giraudeau, M.; Mureithi, N.W.; Pettigrew, M.J. Two-Phase Flow-Induced Forces on Piping in Vertical Upward Flow: Excitation Mechanisms and Correlation Models. J. Press. Vessel. Technol. 2013, 135, 030907. [CrossRef]

19. An, C.; Su, J. Vibration Behavior of Marine Risers Conveying Gas-Liquid Two-Phase Flow. In Proceedings of the Volume 9: Ocean Renewable Energy; ASME International: New York, NY, USA, 2015.

20. Ebrahimi-Mamaghani, A.; Sotudeh-Gharebagh, R.; Zarghami, R.; Mostoufi, N. Dynamics of two-phase flow in vertical pipes. J. Fluids Struct. 2019, 87, 150-173. [CrossRef]

21. Sazesh, S.; Shams, S. Vibration analysis of cantilever pipe conveying fluid under distributed random excitation. J. Fluids Struct. 2019, 87, 84-101. [CrossRef]

22. Khudayarov, B.; Komilova, K.; Turaev, F. Numerical Modeling of pipes conveying gas-liquid two-phase flow. In Proceedings of the E3S Web of Conferences; EDP Sciences: Les Ulis, France, 2019; Volume 97, p. 05022.

23. Zhu, H.; Zhao, H.-L.; Gao, Y. Experimental Investigation of Vibration Response of a Free-Hanging Flexible Riser Induced by Internal Gas-Liquid Slug Flow. China Ocean Eng. 2018, 32, 633-645. [CrossRef]

24. Cabrera-Miranda, J.M.; Paik, J.K. Two-phase flow induced vibrations in a marine riser conveying a fluid with rectangular pulse train mass. Ocean Eng. 2019, 174, 71-83. [CrossRef]

25. Wang, L. A further study on the non-linear dynamics of simply supported pipes conveying pulsating fluid. Int. J. Non-Linear Mech. 2009, 44, 115-121. [CrossRef]

26. Liu, G.; Wang, Y. Natural frequency analysis of a cantilevered piping system conveying gas-liquid two-phase slug flow. Chem. Eng. Res. Des. 2018, 136, 564-580. [CrossRef]

27. Zhang, H.Q.; Wang, Q.; Sarica, C.; Brill, J.P. Unified model for gas-liquid pipe flow via slug dynamics-part 2: Model validation. Trans. ASME J. Energy Resour. Technol. 2003, 125, 274-283. [CrossRef] 